\title{
Avaliação do sistema sanitário da Faculdade ITPAC/Porto
}

O saneamento básico é um instrumento fundamental para a saúde da população, qualidade de vida e para o meio ambiente. Do ponto de vista da engenharia civil, os sistemas sanitários são essenciais durante a fase de projetos de edifícios. Esses projetos de engenharia, voltados para a área de saneamento básico, são denominados de projetos hidrossanitários. Neste contexto, este trabalho traz a problemática: qual a importância da utilização de projetos sanitários na execução dos sistemas prediais coletores de esgoto? O objetivo principal deste trabalho é avaliar o sistema sanitário executado no Instituto Tocantinense Presidente Antônio Carlos de Porto Nacional (TO). A abordagem metodológica será através da avaliação do sistema hidrossanitário da faculdade ITPAC/PORTO, cujo não se utilizou nenhum projeto para implantação destes sistemas. Foram realizadas vistorias técnicas e levantamento de dados sobre as instalações para avaliação das possíveis interferências causadas pela falta dos projetos hidráulico e sanitário e proposição de um projeto sanitário ideal. Por fim, este trabalho ressalta a importância de se adotar um projeto bem elaborado nos sistemas sanitários prediais. Mesmo não exigido pelos órgãos públicos os projetos sanitários elaborados de acordo com as normas possibilitam o correto desempenho do sistema, evitando inconvenientes pós-obras, que podem gerar despesas adicionais com reparos e medidas corretivas.

Palavras-chave: Projeto Sanitário; Saneamento; Desempenho.

\section{ITPAC/Porto Faculty Health System Evaluation}

Sanitation is a fundamental instrument for the population's health, quality of life and the environment. From a civil engineering standpoint, sanitary systems are essential during the design phase of buildings. These engineering projects, focused on the basic sanitation area, are called hydro-sanitary projects. In this context, this work brings the problem: what is the importance of the use of sanitary projects in the execution of sewage collecting building systems? The main objective of this work is to evaluate the sanitary system executed at the Instituto Tocantinense Presidente Antônio Carlos de Porto Nacional (TO). The methodological approach will be through the evaluation of the ITPAC / PORTO water system, whose project was not used to implement these systems. Technical surveys were carried out and data were collected about the facilities to evaluate possible interferences caused by the lack of hydraulic and sanitary projects and the proposition of an ideal sanitary project. Finally, this work highlights the importance of adopting a well-designed project in building sanitary systems. Even if not required by public agencies, sanitary projects prepared in accordance with the standards allow the correct performance of the system, avoiding inconveniences after work, which can generate additional expenses with repairs and corrective measures.

Keywords: Sanitary project; Sanitation; Performance.

Topic: Engenharia Civil

Reviewed anonymously in the process of blind peer.
Received: 10/04/2019

Approved: 11/07/2019
Medson Dewictor Raphael Turibio Aguiar Silva

Instituto Tocantinense Presidente Antônio Carlos, Brasil

http://lattes.cnpq.br/2466832694070399

medson-job@hotmail.com

Diogo Pedreira Lima

Instituto Tocantinense Presidente Antônio Carlos, Brasil

http://lattes.cnpq.br/7967728577417186

diogopedreira@itpac.com.br

Rhaylla Cristielly Rêgo de Sousa

Instituto Tocantinense Presidente Antônio Carlos, Brasil

http://lattes.cnpq.br/1436320238015118

rhayllacristielly@hotmail.com

\section{Referencing this:}

SILVA, M. D. R. T. A.; LIMA, D. P.; SOUSA, R. C. R.. Avaliação do sistema sanitário da Faculdade ITPAC/Porto. Engineering Sciences, v.7, n.2, p.28-39, 2019. DOI: http://doi.org/10.6008/CBPC23183055.2019.002.0004 


\section{INTRODUÇÃO}

O saneamento básico é um instrumento fundamental para a saúde da população, qualidade de vida e para o meio ambiente. Quando se fala em saneamento, existem duas vertentes principais: a primeira é o fornecimento de água potável e encanada à população. Em pleno século 21, ainda existe uma parcela significativa da população mundial que não tem acesso a estes serviços básicos; a segunda vertente principal do saneamento básico é o sistema sanitário de esgoto. Este exerce influência direta na saúde da população, pois condições inadequadas de descartes de dejetos residenciais são as principais causas de surtos de doenças e contaminação dos recursos hídricos naturais.

Do ponto de vista da engenharia civil, os sistemas sanitários são essenciais durante a fase de projetos de edifícios. Esses projetos de engenharia voltados para a área de saneamento básico, são denominados de projetos hidrossanitários. Eles têm por objetivo dimensionar, detalhar, esquematizar, especificar e fornecer todas as informações necessárias para a execução do sistema de abastecimento hidráulico e da rede coletora de esgoto predial.

A construção civil sofreu grandes modificações durante as últimas décadas, cada vez mais a preocupação por sistemas seguros, viáveis economicamente e que tenham uma preocupação ambiental exigidas por lei, por exemplo, as normativas técnicas, ou por exigência de mercado. Outro fator que vem modificando o cenário de projetos de engenharia é o avanço tecnológico. Atualmente existe uma gama muito grande de softwares que tornaram os processos exaustivos e complexos feitos à mão muito mais simples e práticos.

Hoje o processo de projeto de engenharia se encontra em transição, onde muitos projetos já são exigidos por lei, enquanto outros apesar de não serem exigidos legalmente, vem sendo cada vez mais utilizados como garantia de controle durante a execução, economia de materiais, soluções viáveis e redução de problemas de compatibilidade durante a execução, este último, principalmente, pela contribuição da plataforma BIM. Ainda assim, são verificadas muitas obras que não utilizam projetos sanitários para a execução dessas instalações. Neste contexto, o objetivo deste trabalho é avaliar o sistema sanitário executado no Instituto Tocantinense Presidente Antônio Carlos de Porto Nacional (TO).

\section{REVISÃO TEÓRICA}

Segundo Azevedo Netto et al. (2015), o sistema de esgoto sanitário representa o conjunto de instalações e obras que tenham por finalidade coletar, afastar, condicionar e depositar em local adequando os resíduos provenientes das residências de forma contínua e que não exponham às pessoas a agentes nocivos à saúde. $O$ primeiro registro de sistemas coletores de esgoto sanitário executado pelo homem foi em 3000 a.C, na Babilônia. O intuito do sistema era proteger a cidade de enchentes e alagamentos ocasionados pelo aumento das vazões durantes o período chuvoso (BARROS, 2018).

A estrutura era formada por ruas com canais de esgoto feito com tijolos, onde era recebido o esgotamento de banheiras e privadas através do lançamento destes dejetos nos canais. Os sítios 
arqueológicos demonstram que o sistema de drenagem apresentava um nível de profundidade de $50 \mathrm{~cm}$ em relação ao nível da rua, formado por tijolos argamassados e ainda foi verificado banheiros canalizados com manilhas cerâmicas e rejunte de gesso (WEGNER et al., 2018).

Sobre a importância do saneamento básico, Heller (1998) afirma que medidas de saneamento que tenham como foco a melhoria da qualidade da água, contribuem de forma positiva para a redução de riscos à saúde, podendo reduzir em até 4 vezes o número de mortes por doenças que utilizam a água como meio de propagação. Assim, os sistemas de saneamento são de suma importância para manutenção da saúde populacional, proteção do meio ambiente e minimização das consequências da falta de recursos vivida pelas pessoas com renda abaixo do aceitável. Entretanto, o Brasil enfrenta um problema de recursos financeiros disponível para obras de saneamento para algumas regiões menos favorecidas, abaixo é apresentado o índice de atendimento urbano de esgoto no Brasil (TEIXEIRA et al., 2006). Propõe-se a figura 1.

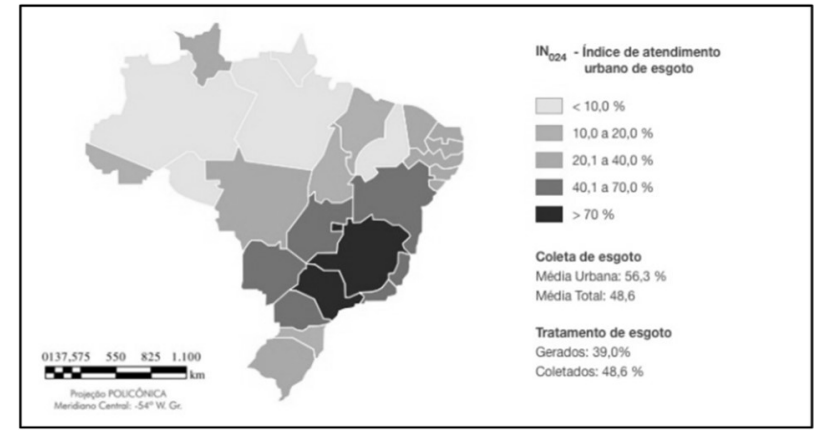

Figura 1: Índice de atendimento urbano de esgoto.

Além dessa grande defasagem do fornecimento de rede de esgoto à população, a grande maioria dos municípios que possuem rede coletora de esgoto não realiza o tratamento dos resíduos e são despejados de forma bruta na natureza, ocasionando poluição dos corpos d'água, que são utilizados como esgoto a céu aberto ou locais de despejos de resíduos sólidos (SOUSA, 2008). O sistema sanitário de esgoto predial é projetado separadamente do projeto hidráulico, visto que a norma estabelece que a rede hidráulica não tenha nenhum tipo de ligação da rede de esgoto. Esse sistema é subdividido nos sistemas de coleta, transporte e de ventilação (BRUCH, 2018).

Sobre os subsistemas de coleta e transporte, são compostos pelos aparelhos sanitário, tubulações e demais acessórios, que têm por finalidade a capitação do esgoto e condução para o destino adequado, seja o coletor público ou fossas sépticas, quando não se dispõe de rede de esgoto público. No dimensionamento destes sistemas é importante analisar os diâmetros e cotas dos ramais. Os principais aparelhos destes sistemas são os vasos sanitários, lavatório, maquinas de lavar louça e roupa e a pia de cozinha (ABNT, 1999).

Dentro do sistema de esgoto, um dos maiores causadores de problemas de desempenho é o mal funcionamento dos fechos hídricos, que ocasiona o retorno dos gases presentes no esgoto para o interior das edificações (SANTOS et al., 1998). Esses problemas estão associados geralmente a defeitos dos próprios desconectores pelo fim da vida útil, ou principalmente pela ocorrência de sifonagem induzida, que retira o fecho hídrico através da pressão negativa formada ao dar descarga na tubulação primária (SANTOS et al., 1998). 
Os gases presentes no sistema de esgoto são altamente prejudiciais à saúde e o retorno desses gases para os interiores das edificações são proibidos por norma (ABNT, 1999). Esses gases são provenientes do processo de decomposição (aeróbico e anaeróbico) e pode conter gases como o metano, óxido de nitrogênio e óxidos sulfídricos. Além dessas substâncias emitidas, estão presentes no ar bactérias patogênicas, que podem ocasionar quadros clínicos complicados (LILIAMTIS et al., 2003).

Segundo Creder (2006), o sistema de ventilação presente nas instalações de prediais de esgota tem justamente a função de aliviar a pressão dos condutores dentro sistema e ainda conduzir estes gases para a atmosfera. Esse sistema deve possuir uma inclinação mínima de 1\% para garantir que nenhum liquido possa escoar pela tubulação de ventilação, que devem ser instaladas acima da tubulação de esgoto. A destinação final do esgoto deve ser a rede coletora pública que procederá com os tratamentos desse efluente até que possa ser devolvido ao meio ambiente provocando o mínimo de impacto ambiental possível. Nos casos em que a região onde se encontra a edificação não conta com sistema público de coleta de esgoto, deve-se ser previsto algum método de proteção ao meio ambiente e aos mananciais hídricos dos rejeitos gerados (ABNT, 1997).

As fossas sépticas é uma opção muito usual para os sistemas de tratamento de esgoto local. Elas são unidades que podem ter forma cilíndrica, prismática o retangular. Os processos de tratamento utilizados são o de digestão, flotação e sedimentação. A profundidade mínima dos tanques é de 1,20m para garantir neutralização das bactérias, o funcionamento geral de um tanque séptico é descrito na figura 6 (SOUSA; MELO, 2017).

\section{METODOLOGIA}

\section{Caracterização do local de pesquisa}

O Instituto Tocantinense Presidente Antônio Carlos Porto (ITPAC/Porto Nacional) é inscrito no Cadastro Nacional de Pessoas Jurídicas do Ministério da Fazenda (CNPJ) sob o no 10.261.569/0001-64. Foi credenciada pelo Decreto Estadual no 3.486, de 04 de setembro de 2008, publicado no Diário Oficial do Estado do Tocantins no 2.728, em 05 de setembro de 2008. A FAPAC, credenciada em 2008, contribui de forma significante no desenvolvimento do município de Porto Nacional (TO) através de implementação de atividades de ensino, extensão, pesquisa e de responsabilidade socioambiental.

O campus de Porto Nacional (TO) está localizado na Rua 02, Quadra 07, s/no, Setor Jardim dos Ypês em Porto Nacional (TO). Possui uma área abrangente de 79.905,80 $\mathrm{m}^{2}$, sendo $9.025,46 \mathrm{~m}^{2}$ de área construída, dividida em Blocos: Gama, Beta, Delta, Phi, Kapa, Sigma, Tau, Epsilon e Ômega, com estacionamento amplo de $18.495,65 \mathrm{~m}^{2}$ de pavimentação asfáltica. A Instituição possui infraestrutura adaptada para o atendimento aos alunos e demais usuários Portadores de Necessidades Especiais-PNE. O seu espaço físico conta com banheiros adaptados, rampas de acesso, piso tátil e identificação em todas as portas escrito em braile nas principais entradas, contando, ainda, com vagas prioritárias no estacionamento. 
Para este trabalho, foram utilizados apenas os blocos Beta, Gama e Delta como ambientes de avaliação do sistema sanitário. Foi dada preferência a esses blocos por atenderem a maior quantidade de usuários, pois se tratam dos blocos em que se encontram as salas de aulas, e não utilizaram projeto sanitário na sua execução. Foram excluídos ainda os blocos de atendimentos clínicos e laboratórios, por apresentarem riscos de saúde durante a realização das vistorias.

\section{Levantamento de dados}

Em seguida, foi realizado o levantamento de dados sobre o processo de execução e as condições atuais do sistema de esgoto da instituição. Para a avaliação do sistema sanitário, existe uma grande dificuldade em visualização das suas componentes visto que se encontram embutidas na edificação e realizar perfurações apenas para verificação de desempenho é inviável. Assim, foi necessário utilizar de outros meios para avaliação de desempenho do sistema de esgoto do ITPAC-Porto. Inicialmente, foi realizado um questionário com as colaboradoras que trabalham na limpeza destes blocos. Atualmente são duas profissionais que atuam em turno único no bloco DELTA e quatro profissionais que se revezam em dois turnos para os blocos Beta e Gama.

O questionário consistiu em sete perguntas a respeito do estado de funcionamento do sistema sanitário. Basicamente, o intuito desde questionário era verificar se os gases provenientes do esgoto estavam voltando para a edificação. A escolha desse método foi porque as colaboradoras estão em contado direto com a banheiro assim que eles são limpos e caso identificado a presença de odores de esgoto logo após a limpeza indica que existe alguma falha no sistema sanitário.

Em seguida, foram realizadas as vistorias nos banheiros para verificar o estado de funcionamento dos desconectores. Nesta verificação, foram utilizadas luvas de proteção e chave de fenda para retirada das grelhas das caixas sifonadas, foram realizados testes ligando os aparelhos sanitários, realizou-se ainda os registros fotográficos e anotações em prancheta do estado de funcionamento dos componentes e os erros encontrados.

Para a verificação da existência de tubulações de ventilação no sistema de esgoto, também foi necessário utilizar um método alternativo uma vez que instalado o sistema estaria embutido. Nesse caso, foram utilizadas fotografias aéreas das coberturas dos respectivos blocos para verificar a presença de terminais de ventilação. Para realização das fotos foi utilizado um drone modelo Phanton 3 Stardard com câmera de 12 megapixel, sensor A 1/2,3 com abertura de f/2,8 na lente principal e resolução full HD.

\section{Elaboração de projeto}

Para elaboração do projeto sanitário ideal do ITPAC-Porto, foi utilizado o software Hydros. Este programa foi desenvolvido pela empresa Autoqi, sendo destinado para elaboração de projetos hidrossanitários. O aplicativo possui um modelo eletrônico completo das tubulações de esgoto e peças de utilização. O Hydros permite visualização em planta e detalhes, o dimensionamento, a verificação de preções e fornece uma lista de materiais precisa. As plantas obtidas foram exportas em formatado dwg para o Hydrus, 
utilizando as próprias ferramentas do software que atende as normas brasileiras relacionados a projetos sanitários prediais, com os dados disponíveis da edificação realizou se o dimensionamento e o detalhamento do projeto ideal para os referidos blocos.

\section{RESULTADOS}

Os resultados obtidos através de entrevistas com as colaboradoras que trabalham na limpeza dos blocos permitiram constatar que em todos os blocos é comum os banheiros exalarem mal odores, mesmo logo após serem limpos. Dos blocos analisados, o que apresenta maior exalação de odor, segundo as entrevistadas, é o bloco Gama.

Também foi relatado que, mesmo nas férias, quando os banheiros eram raramente utilizados pelo público, era evidenciado os odores de esgoto. Quando indagado sobre as medidas mitigadoras da Instituição, quanto a esse problema, as colaboradoras afirmaram que geralmente é realizada a limpeza das fossas sépticas, que amenizam os odores. Também são utilizadas partilhas para aromatização do ambiente. Durante as vistorias, também foi identificado, através do relato de um colaborador, que no bloco Delta foi necessária a instalação de uma coluna de ventilação próxima ao tanque séptico, devido ao retorno dos odores da fossa para dentro da edificação. Com base nesta informação constata-se que as caixas de passagens também não estavam funcionando de forma adequada, pois estas devem ser executadas com fecho hídrico para que os gases provenientes do sistema de tratamento não retornem.

\section{Vistorias e relato fotográfico interno: Bloco Beta}

Será apresentada a análise do banheiro masculino e feminino do Bloco Beta. Durante a vistoria, verificou-se que as caixas sifonadas são de PVC com diâmetro de $150 \mathrm{~mm}$ e apresentam 3 entradas de diâmetro de 40mm e uma saída de 50mm, são equipadas com grelha de PVC e um extensor como observadas nas imagens. Essa configuração é observada em todas caixas sifonadas das edificações. Nos banheiros femininos do Bloco Beta, foi verificado que as janelas, por mais que permitam uma boa iluminação do ambiente, não possuem um desempenho tão bom na circulação de ar.

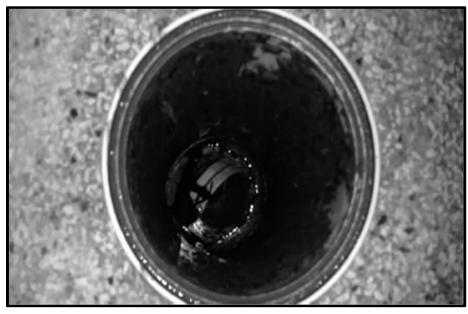

Figura 2: Caixa sifonada do 20 banheiro feminino do Beta.

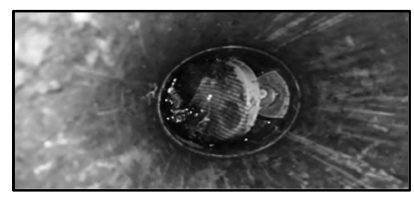

Figura 4: Caixa sifonada do 2으 banheiro masculino do Beta.

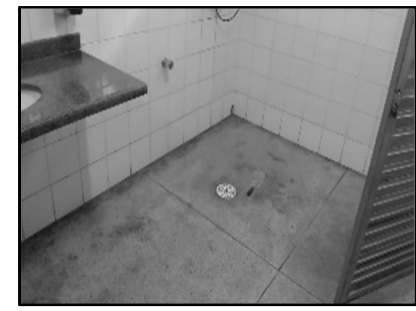

Figura 3: Caixa sifonada do 2o banheiro masculino do Beta.

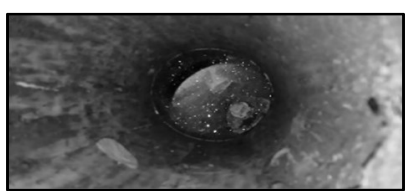

Figura 5: Caixa sifonada do 10 banheiro masculino do Beta. 


\section{Blocos Gama e Delta}

No bloco Gama, o banheiro feminino apresentou uma boa abertura das janelas que permitem uma maior circulação de ar. Quanto à caixa sifonada analisada, observou-se a inexistência do sifão, como demostrado na figura 6, assim como nos outros banheiros não existe fecho hídrico, ocasionando o retorno dos gases do esgoto para a edificação. No banheiro masculino do bloco Gama, foi registrado o maior número de erros de desempenho e de execução no sistema sanitário. O primeiro erro identificado foi a execução incorreta de uma caixa sifonada com grelha nos mictórios descritas na figura 7. Esta prática está em desacordo com a NBR-8160, que prevê caixas sifonadas com tampa cega para os mictórios.

Na segunda caixa sifonada deste banheiro, também foi verificada a presença de problemas de desempenho. Ao contrário dos outros blocos esta caixa sifonada não apresentava o sifão danificado. Entretanto, o mesmo se encontrava mal encaixado e sem nenhuma presença de água (figura 9), tendo sua função de desconector inviabilizadas. No bloco Delta, foi verificada a maioria dos problemas encontrados nos outros blocos. Ambos os banheiros apresentam pouca capacidade de ventilação, devido ao modelo das janelas. No banheiro masculino, foi verificada que a tampa do sifão estava quebrada (figura 10), e no banheiro feminino nem sequer existia tais componentes (figura 11), o que ocasiona o retorno dos gases para a edificação.

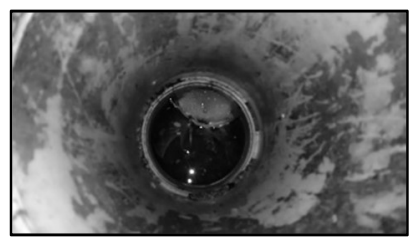

Figura 6: Caixa sifonada do banheiro feminino do Gama.

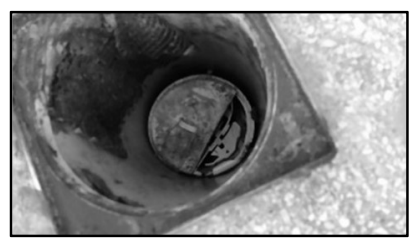

Figura 8: Execução incorreta de caixa sifonada no banheiro masculina do Gama.

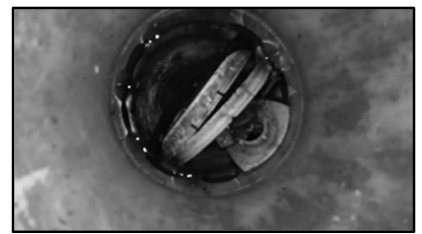

Figura 10: Caixa sifonada sem fecho hídrico no banheiro masculino do Delta.

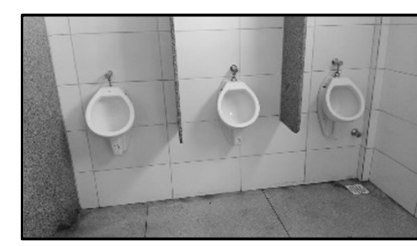

Figura 7: Execução incorreta de caixa sifonada no banheiro masculino do Gama.

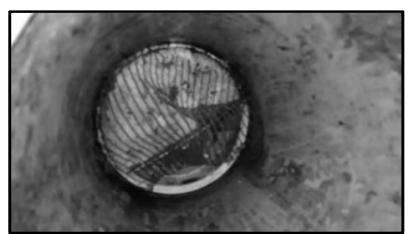

Figura 9: Caixa sifonada sem fecho hídrico no banheiro masculino do Gama.

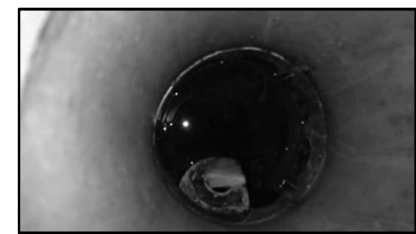

Figura 11: Caixa sifonada sem fecho hídrico no banheiro feminino do Delta.

\section{Relato fotográfico aéreo}

Na figura 12, é apresentado o relato fotográfico realizado utilizando o drone Phanton 3 Standard, com objetivo de verificar a existência de terminais de ventilação no telhado das edificações, visto que foi o único método disponível para verificação, uma vez que os blocos não possuem projetos sanitários para 
realizar. O método também se mostrou eficiente por não envolver riscos de acidentes físicos, como no caso a verificação a olho nu que necessitaria que alguém subisse até o telhado.

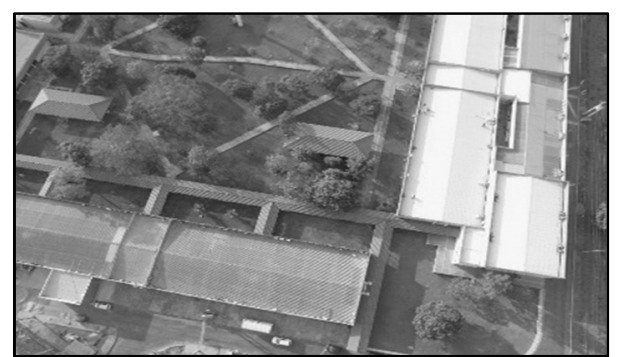

Figura 12: Vista aérea do telhado dos Blocos Beta, Gama e Delta.

Através da visualização das imagens aéreas em alta resolução do telhado dos Blocos Beta, Gama e Delta, foi possível utilizar ferramentas de zoom, sem a perda de definição, para verificar a existência dos terminais de ventilação. Após análise, concluiu-se que nenhum dos blocos apresentam terminais de ventilação que emita os gases provenientes do esgoto para a atmosfera, com exceção do Bloco Delta que possui uma coluna de ventilação próxima a fossa séptica, instalado posterior a conclusão da obra. Nas figuras 13 e 14, tem-se a elaboração de projeto sanitário do Bloco Beta. Já nas figuras 15 e 16, dos Blocos Gama e Delta, respectivamente.

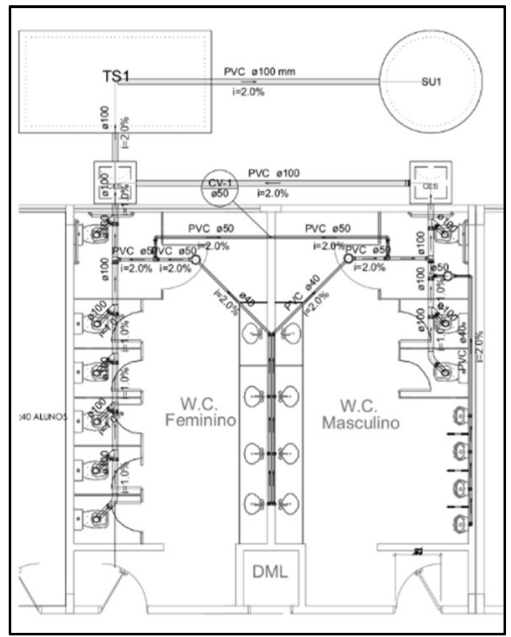

Figura 13: Projeto sanitário do banheiro 1 do Beta. Figura 14: Projeto sanitário do banheiro 1 do Beta.

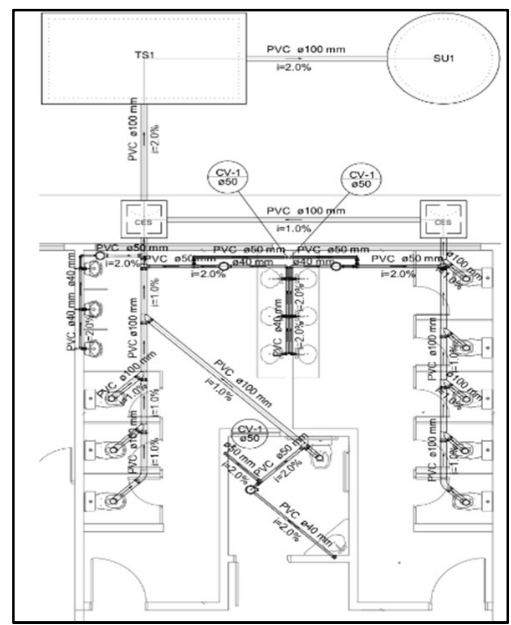

Figura 15: Projeto sanitário do banheiro do Gama.
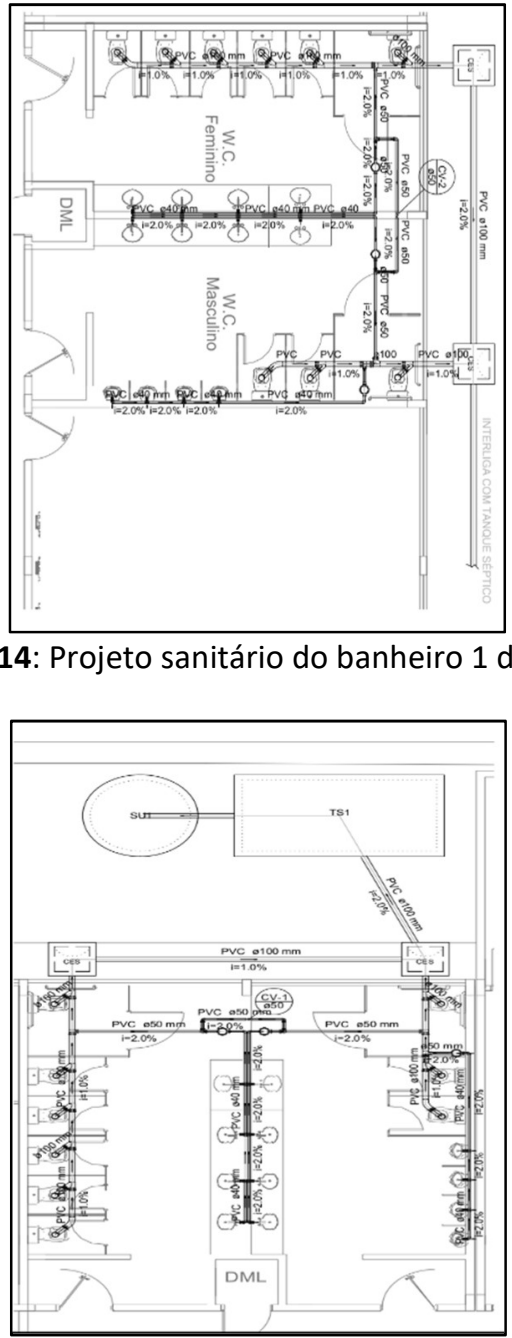

Figura 16: Projeto sanitário do banheiro do Delta. 


\section{DISCUSSÃO}

\section{Dimensionamento e detalhamento dos tanques sépticos e sumidouros}

O dimensionamento do sistema local de deposição final de esgoto foi realizado também com o auxílio do software Hydros. Para determinação da população foi utilizado a soma da capacidade de alunos de cada sala dos blocos. Dentre estes optou pelo bloco com maior capacidade sendo o beta, com 826 pessoas. Sendo aplicado as dimensões obtidas para a fossa séptica e sumidouro nos demais blocos com intuito de fornecer uma padronização de dimensões.

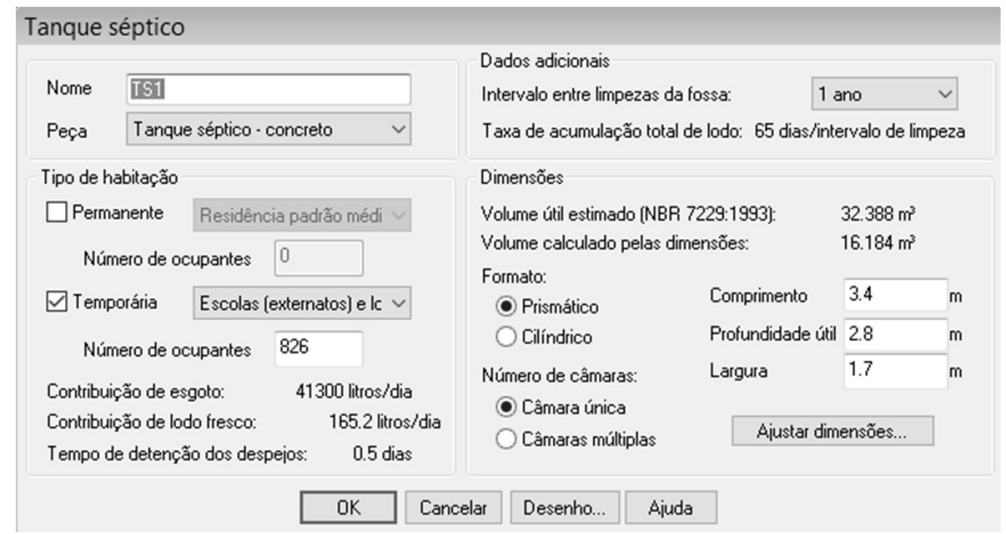

Figura 17: Projeto sanitário do banheiro do DELTA.

O detalhamento completo da alimentação dos dados no software está descrito na figura 17. É observado que o volume útil estimado de norma é superior as dimensões adotadas. A escolha dessas dimensões se deu pelo espaço reduzido de implantação dos tanques sépticos, sendo necessário a escolha de dimensões reduzidas, visto que as estruturas devem ser implantadas a uma distância mínima de 1,5m. Por consequência o intervalo de tempo entre as limpezas da fossa que seria de 1 ano, devem ser executadas a cada 6 meses, para correto funcionamento do sistema.

Os resultados obtidos no dimensionamento das fossas sépticas e sumidouros não poderão ser comparados com as dimensões executadas no campus, pois ela não possui projetos para a verificação e por estarem em funcionamento, impossibilita a medição da profundidade executada.

Com base nos resultados obtidos na vistoria do sistema sanitário presentes nos blocos que possuem sala de aula (Beta, Gama e Delta), pode-se verificar que todas as caixas sifonadas vistoriadas apresentaram pelo menos um problema de funcionamento. Segundo a ABNT (1999), todas os aparelhos sanitários devem estar protegidos por desconectores. O mal funcionamento destes dispositivos acarretam no retorno dos gases do esgoto para o interior da edificação.

Os resultados corroboram com o relato dos colaboradores que identificaram a presença do retorno de odores provenientes do sistema de esgoto. De acordo com Conceição (2007), as principais causas da presença de odores nas áreas molhadas estão relacionadas ao mal funcionamento nos sifões dos aparelhos sanitários, aos projetos mal elaborados ou à ocorrência de fenômenos que inutilizam o fecho hídrico, como a evaporação, a autossifonagem, e a sifonagem induzida. 


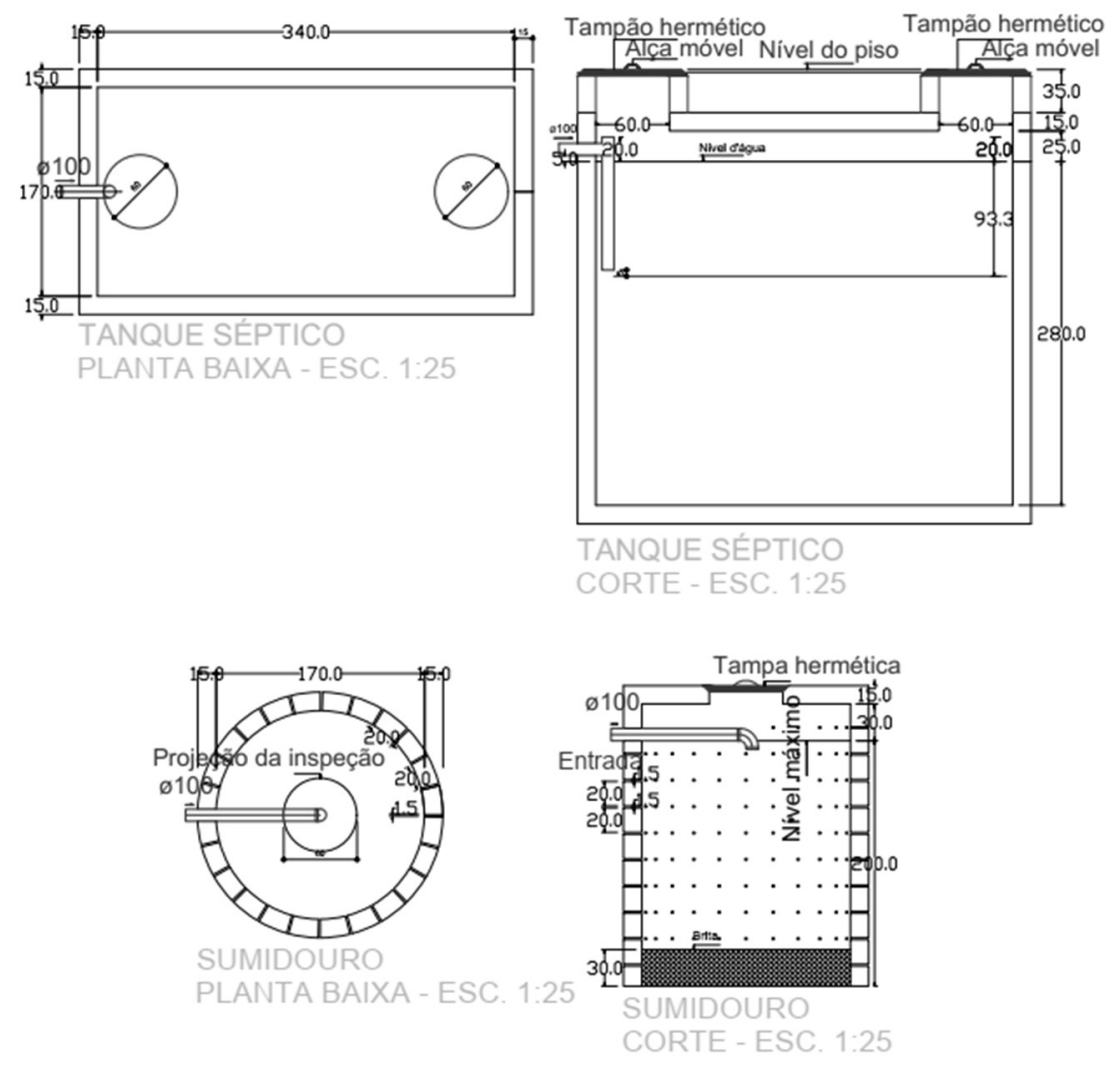

Figura 18: Detalhamento das fossas sépticas.

Quanto à proteção dos fechos hídricos, não foi encontrada tubulações de ventilação no sistema de esgoto, que tem por função evitar a ocorrência de sifonagem nos desconectores. Esta prática é considerada inadequada, de acordo com a ABNT (1999), que estabelece a necessidade de assegurar a manutenção do fecho hídrico dos desconectores mediantes as solicitações impostas durante o estado de serviço dos componentes.

Outra inconformidade verificada através da vistoria foi a instalação de uma caixa sifonada com grelha nos mictórios do banheiro masculino do Bloco Gama. A ABNT (1999) especifica que as caixas sifonadas que recebem despejos de mictório devem possuir tampa cega. O fecho hídrico funciona, pois os gases não são solúveis em água. Entretanto, no caso da urina, ocorre a dissolução no fecho hídrico, e ele começa a emitir odores. Por isso, nesses casos, deve-se optar por tampas cegas, e não tampas com grelhas, como a utilizada. As fossas sépticas também exercem um papel fundamental no correto funcionamento do sistema de esgoto. A norma ABNT (1993) estabelece que elas devem possuir uma profundidade mínima de 1,2m e a distância mínima do fundo para o lençol freático deve ser de 1,5m. Neste estudo de caso não possível fazer a avaliação das profundidades das fossas executadas na instituição.

Quanto às distâncias horizontais mínimas, a ABNT (1993) determina que as fossas sépticas devem ser alocadas a 1,5m de construções, a $3 \mathrm{~m}$ de arvores a $15 \mathrm{~m}$ de poços freáticos. No campus do ITPAC-Porto, todos as fossas atendem as distâncias mínimas horizontais. Entretanto, nos blocos observados, as fossas se localizam a menos de $4 \mathrm{~m}$ das edificações. Então, durante o processo de execução, deveria ter sido priorizado a instalação de sistemas que poderiam impedir o retorno dos gases produzidos tanto pelo sistema de esgoto primários, quanto pelas próprias fossas sépticas. 
Apesar de o projeto realizado de acordo com a norma ABNT (1999) atender todos os requisitos de desempenho, a implantação desse sistema em uma edificação já executada gera custos elevados e tornam altamente trabalhosas as intervenções. Assim, pode ser trabalhado como solução não convencional a utilização de Válvulas de Admissão de $\operatorname{Ar}$ (VAA) em substituição ao sistema de ventilação secundária.

Segundo Fernandes et al. (2002), as válvulas de admissão de ar são dispositivos que funcionam ao abrirem e admitirem a entrada de ar para o interior das tubulações, quando ocorrem pressões negativas pelo escoamento de aparelhos sanitários e se fecham na presença de pressão positiva. Esse processo previne a ocorrência de sifonagem. $O$ estudo de Fernandes et al. (2002) permitiu concluir que as VAA podem ser utilizadas em substituição as colunas de ventilação secundária em edifícios de até 8 pavimentos.

\section{CONCLUSÕES}

Com base nos resultados obtidos, conclui-se que os Blocos Beta, Gama e Delta do Instituto Tocantinense Presidente apresenta problemas de desempenho no sistema sanitário. No geral, foram identificados problemas nos desconectores de praticamente todos os banheiros vistoriados. também se verificou que foram executadas algumas práticas fora de norma como a execução de caixas sifonadas com grelha em mictórios no Bloco Gama. Outra problemática observada foi a falta de execução de sistemas de ventilação nas tubulações de esgoto, que tem por finalidade a proteção dos fechos hídricos, impedindo o processo de sifonagem.

No geral, os problemas de desempenho acarretaram no retorno dos gases provenientes do esgoto, verificado através dos relatos dos colaboradores, em que se identificou que o Bloco Gama foi o bloco que mais apresentava problemas de exalação de odores, corroborando com os resultados que mostram que o bloco foi o que mais registrou inadequações do sistema sanitário. A presença de odores pelo retorno dos gases gera desconforto aos usuários do ambiente e além do fator social, esses gases possuem substâncias tóxicas e/ou agentes patogênicos como vírus e bactérias que podem provocar problemas graves de saúde, sendo recomendado a realização de intervenções que possibilitem o correto isolamento desses gases no sistema sanitário.

As recomendações para intervenções nos blocos citados é a revitalização através das caixas sifonadas, sendo necessário trocar os sifões danificados, corrigir as caixas que se encontram entupidas e garantir o correto funcionamento dos fechos hídricos. Como o sistema de ventilação proposto em projeto é de difícil execução, quando a edificação já está de pé, as VAAs podem ser uma solução eficiente na substituição do sistema de ventilação secundário. Ainda assim, é recomendado executar colunas de ventilação primárias próximas aos tanques sépticos, como executada no Bloco Delta.

Por fim, este trabalho ressalta a importância de se adotar um projeto bem elaborado nos sistemas sanitários prediais. Mesmo não exigido pelos órgãos públicos os projetos sanitários elaborados de acordo com as normas possibilitam o correto desempenho do sistema, evitando inconvenientes pós-obra que podem gerar despesas adicionais com reparos e medidas corretivas. 


\section{REFERÊNCIAS}

ABNT. Associação Brasileira de Normas Técnicas. NBR 13969: Tanques sépticos: Unidades de tratamento complementar e disposição final dos efluentes líquidos: Projeto, construção e operação (Septic Tank-Units for Treatment and Disposal of Liquid Effluents-Project, Construction and Operation). Rio de Janeiro: ABNT, 1997.

ABNT. Associação Brasileira de Normas Técnicas. NBR 7229: Projeto, construção e operação de sistemas de tanques sépticos. Rio de Janeiro: ABNT, 1993.

ABNT. Associação Brasileira de Normas Técnicas. NBR 8160: Sistemas prediais de esgoto sanitário: Projeto e execução. Rio de Janeiro: ABNT, 1999.

\section{AZEVEDO NETTO, J. S.; FERNÁNDEZ, M. F.. Manual de} hidráulica. São Paulo: Blucher, 2015.

\section{BARROS, R.. A história do Saneamento Básico na Idade} Antiga. Rio de Janeiro: 2018.

BRUCH, J. T.. Projeto de instalações hidrossanitárias com aquecimento solar e aproveitamento de água pluvial em uma edificação residencial multifamiliar. Florianópolis: UFSC, 2018.

CONCEIÇÃO, A. P.. Estudo da incidência de falhas visando a melhoria da qualidade dos sistemas prediais hidráulicos $\mathbf{e}$ sanitários. Dissertação (Mestrado) - Universidade Federal de São Carlos, São Carlos, 2007.

CREDER, H.. Instalações hidráulicas e sanitárias. 6 ed. Rio de Janeiro: Livros Técnicos e Científicos, 2006.

FERNANDES, V. M. C.; GONÇALVES, O. M.. Análise do uso de válvulas de admissão de ar nos sistemas de esgotos sanitários brasileiros. Ambiente Construído, v.2, n.4, p.1926, 2002.
HELLER, L.. Relação entre saúde e saneamento na perspectiva do desenvolvimento. Ciência \& Saúde Coletiva, v.3, p.73-84, 1998

LILIAMTIS, T. B.; MANCUSO, P. C. S.. A geração de maus odores na rede coletora de esgotos do município de Pereira Barreto: um problema de saúde pública. Saúde e Sociedade, v.12, p.86-93, 2003.

SANTOS, D. C.; GONÇALVES, O. M.. Contribuições para a Estruturação de Modelo Aberto para o Dimensionamento Otimizado dos Sistemas Prediais de Esgotos Sanitários. São Paulo: EPUSP, 1998.

SOUSA, L.. Problemas ambientais urbanos: desafios para a elaboração de políticas públicas integradas. Cadernos Metrópole, v.1, n.1, p.27-47, 2008.

SOUZA, G.; MELO, S. P.. Estudo das manifestações patológicas em instalações prediais de água fria e de esgoto sanitário de edificação residencial privativa multifamiliar. Tubarão: UNISUL, 2017.

TEIXEIRA, J. C.; GUILHERMINO, R. L.. Análise da associação entre saneamento e saúde nos estados brasileiros, empregando dados secundários do banco de dados indicadores e dados básicos para a saúde 2003-IDB 2003. Engenharia Sanitária e Ambiental, v.11, n.3, p.277282, 2006.

WEGNER, C.; BASCHERA, W. L.; DUSI, L.. Análise da utilização da rede de esgoto sanitário pelos residentes do Loteamento Ulisses Guimarães, no município de Caçador/SC. Ignis: Periódico Científico de Arquitetura e Urbanismo, Engenharias e Tecnologia da Informação, v.6, n.3, p.27-47, 2018.

A CBPC - Companhia Brasileira de Produção Científica (CNPJ: 11.221.422/0001-03) detém os direitos materiais desta publicação. Os direitos referem-se à publicação do trabalho em qualquer parte do mundo, incluindo os direitos às renovações, expansões e disseminações da contribuição, bem como outros direitos subsidiários. Todos os trabalhos publicados eletronicamente poderão posteriormente ser publicados em coletâneas impressas sob coordenação da Sustenere Publishing, da Companhia Brasileira de Produção Científica e seus parceiros autorizados. Os (as) autores (as) preservam os direitos autorais, mas não têm permissão para a publicação da contribuição em outro meio, impresso ou digital, em português ou em tradução. 